\title{
Hemoglobin Differences in Uncomplicated Monochorionic Twins in Relation to Birth Order and Mode of Delivery
}

\author{
Lianne Verbeek, ${ }^{1}$ Depeng P. Zhao, ${ }^{1}$ Arjan B. te Pas, ${ }^{1}$ Johanna M. Middeldorp, ${ }^{2}$ Stuart B. Hooper, ${ }^{3,4}$ \\ Dick Oepkes, ${ }^{2}$ and Enrico Lopriore ${ }^{1}$ \\ ${ }^{1}$ Division of Neonatology, Department of Pediatrics, Leiden University Medical Center, Leiden, the Netherlands \\ ${ }^{2}$ Department of Obstetrics, Leiden University Medical Center, Leiden, the Netherlands \\ ${ }^{3}$ Ritchie Centre, Hudson Institute of Medical Research, Melbourne, Victoria, Australia \\ ${ }^{4}$ Department of Obstetrics \& Gynaecology, Monash University, Melbourne, Victoria, Australia
}

\begin{abstract}
Aim: To determine the differences in hemoglobin $(\mathrm{Hb})$ levels in the first 2 days after birth in uncomplicated monochorionic twins in relation to birth order and mode of delivery. Methods: All consecutive uncomplicated monochorionic pregnancies with two live-born twins delivered at our center were included in this retrospective study. We recorded $\mathrm{Hb}$ levels at birth and on day 2, and analyzed $\mathrm{Hb}$ levels in association with birth order, mode of delivery, and time interval between delivery of twin 1 and 2. Results: A total of 290 monochorionic twin pairs were analyzed, including 171 (59\%) twins delivered vaginally and 119 (41\%) twins born by cesarean section (CS). In twins delivered vaginally, mean $\mathrm{Hb}$ levels at birth and on day 2 were significantly higher in second-born twins compared to first-born twins: 17.8 versus $16.1 \mathrm{~g} / \mathrm{dL}$ and 18.0 versus $14.8 \mathrm{~g} / \mathrm{dL}$, respectively $(p<.01)$. Polycythemia was detected more often in second-born twins $(12 \%$, $20 / 166)$ compared to first-born twins $(1 \%, 2 / 166 ; p<.01)$. Hb differences within twin pairs delivered by CS were not statistically or clinically significant. We found no association between inter-twin delivery time intervals and $\mathrm{Hb}$ differences. Conclusions: Second-born twins after vaginal delivery have higher $\mathrm{Hb}$ levels and more often polycythemia than their co-twin, but not when born by CS.
\end{abstract}

Keywords: Monochorionic twins, hemoglobin, vaginal delivery, cesarean section, umbilical cord clamping

Placental vascular anastomoses are extremely rare in dichorionic twins, but almost ubiquitous in monochorionic twins. These vascular anastomoses allow antenatal inter-twin blood transfusion and may lead to severe complications such as twin-twin transfusion syndrome (TTTS) or twin anemia-polycythemia sequence (TAPS). However, in most monochorionic twins, inter-twin blood transfusion between the two fetuses is 'balanced' and the pregnancy evolves without complications until birth. During birth, acute shifts of blood through the vascular anastomoses may also occur and lead to large $\mathrm{Hb}$ differences between the two neonates (Lopriore et al., 2005; 2014). A few small studies in uncomplicated monochorionic twins reported significantly higher $\mathrm{Hb}$ levels in second-born twins compared to firstborns, suggesting a possible role for intrapartum placentofetal transfusion (Faxelius et al., 1977; Klebe \& Ingomar, 1972; Lopriore et al., 2005). However, these studies are limited by small sample sizes, hampering the interpretation of the results and the evaluation of possible risk factors.
The aim of this study was to evaluate the $\mathrm{Hb}$ differences at birth in a large cohort of uncomplicated monochorionic twins and determine the effect of birth order, mode of delivery, and time-interval to delivery between twin 1 and twin 2 .

\section{Methods}

All consecutive monochorionic twins delivered at our tertiary care center between May 2002 and October 2015 were included in this retrospective study. We excluded monochorionic twins affected by TTTS, TAPS, twin reversed arterial perfusion sequence (TRAP) or single or double fetal

RECEIVED 22 January 2016; ACCEPTED 20 February 2016. First published online 14 April 2016.

ADDRESS FOR CORRESPONDENCE: Lianne Verbeek, Department of Pediatrics, Leiden University Medical Center, J6-S, Albinusdreef 2, 2333 ZA, Leiden, the Netherlands. E-mail:1.i.verbeek@lumc.nl 


\section{TABLE 1}

Baseline Characteristics

\begin{tabular}{|c|c|c|}
\hline & Twin pairs delivered vaginally $(n=171)$ & Twin pairs delivered through CS $(n=119)$ \\
\hline Gestational age at birth - weeks & $34.6 \pm 3.0$ & $33.2 \pm 2.8$ \\
\hline Birth weight $-\mathrm{gr}^{\mathrm{a}}$ & $2,167 \pm 610$ & $1,821 \pm 650$ \\
\hline Birth weight discordance $-\%^{a}$ & $9.8(3.8-17.8)$ & $16.7(7.8-30.2)$ \\
\hline Female - no. (\%) & $89(52 \%)$ & $58(49 \%)$ \\
\hline Delivery time interval - minutes $^{a}$ & $9(5-16)$ & $2(1-2)$ \\
\hline
\end{tabular}

Note: ${ }^{a}$ Value given as mean $\pm S D$ or median (IOR).

demise. Similarly, when the first twin was delivered vaginally and the co-twin through secondary CS, the twin pair was also excluded. We defined TTTS according to the Eurofoetus criteria, with a cut-off at a deepest vertical pocket of amniotic fluid in the donor at $\leq 2 \mathrm{~cm}$ and in the recipient of $\geq 8 \mathrm{~cm}$ within the first 20 weeks of gestation or $\geq 10 \mathrm{~cm}$ after gestational week 20 (Senat et al., 2004). The definition of TAPS was based on the presence of inter-twin $\mathrm{Hb}$ difference $>8 \mathrm{~g} / \mathrm{dL}$ and at least one of the following criteria: reticulocyte count ratio $>1.7$ or placenta injection with colored dye showing only minuscule anastomoses (diameter $<1 \mathrm{~mm}$; Slaghekke et al., 2010).

$\mathrm{Hb}$ levels were routinely assessed at birth from umbilical cord blood or venous blood directly from the neonate when umbilical cord blood could not be used. Since Hb levels are subject to significant change in the first few hours after birth, and in particular in cases with acute large shifts due to intrapartum blood transfusion, we also recorded $\mathrm{Hb}$ levels on day 2 (Lopriore et al., 2005). The following perinatal data was collected: gestational age at birth, mode of delivery (CS or vaginal delivery), and time interval between delivery of the first twin and the second twin (in minutes). We were not able to record the timing of cord clamping as this is not routinely registered in deliveries occurring at our center. Local guidelines recommend cord clamping at 60-90 s, but this varies in practice.

The following neonatal data were collected: gender, birth weight, birth weight discordance, occurrence of polycythemia, treatment with partial exchange transfusion or red blood cell transfusion in the first 2 days of life, and neonatal mortality. Birth weight discordance was calculated by dividing the difference in birth weight between twins by the birth weight of the larger twin. Polycythemia was defined as a venous hematocrit level $>65 \%$. Neonatal mortality was defined as death within 28 days after birth. Acute peripartum TTTS was defined as an $\mathrm{Hb}$ difference of at least $8 \mathrm{~g} / \mathrm{dL}$ at birth, without signs of TAPS or chronic TTTS (Lopriore et al., 2014). In case of polycythemia, partial exchange transfusion was performed when venous hematocrit $>70 \%$ in asymptomatic patients or hematocrit $>65 \%$ in symptomatic patients (Rosenkrantz, 2003).

The primary outcome of the study was inter-twin $\mathrm{Hb}$ differences at birth and day 2. Data were analyzed in association with birth order, mode of delivery, and time interval between delivery of twin 1 and twin 2 .
The hospital's Research Ethics Committee approved the study (protocol number: P15.325).

\section{Statistics}

Data are reported as means and standard deviations $(S D)$ or as medians and interquartile ranges (IQR), as appropriate. Continuous values within twin pairs were analyzed using the paired $t$ test. Paired nominal data were analyzed using the McNemar test. Unpaired continuous data were analyzed using the Mann-Whitney Test. For comparing unpaired nominal data, the chi-square test was used. The Spearman correlation coefficient was used to study the relationship between time interval at birth between the first-born twin and the second-born twin and $\mathrm{Hb}$ levels. A $p$ value $<.05$ was considered to be statistically significant. SPSS version 20 was used for performing the analysis (SPSS, Inc., Chicago, Illinois, USA).

\section{Results}

A total of 290 monochorionic twin pairs were analyzed in this retrospective study, including 171 (59\%) twin pairs delivered vaginally and 119 (41\%) pairs born through CS. Baseline characteristics of the population are shown in Table 1.

At birth, paired $\mathrm{Hb}$ samples were available in $143(84 \%)$ twin pairs in the vaginal delivery group and 115 (97\%) twin pairs in the CS group. On day 2, paired $\mathrm{Hb}$ samples were available in $89(52 \%)$ vaginally born twin pairs and 67 $(56 \%)$ in the CS group. Hb levels in relation to birth order and mode of delivery are presented in Table 2. Mean $\mathrm{Hb}$ levels at birth were significantly higher in second-born twins when delivered vaginally, but no differences were detected between twin 1 and 2 when delivered through CS. Inter-twin $\mathrm{Hb}$ differences were significantly larger in twins delivered vaginally compared to CS, 1.9 (IQR: $0.6-3.9$ ) g/dL versus 1.1 (IQR: $0.4-3.1) \mathrm{g} / \mathrm{dL}(p=.02)$.

On day 2, inter-twin $\mathrm{Hb}$ differences increased and became more evident in twins born vaginally. Second-born twins had a higher $\mathrm{Hb}$ level in $70 \%(100 / 143)$ of cases at birth and $80 \%(74 / 93)$ on day 2 after vaginal birth. In the CS group, second-born twins had a higher $\mathrm{Hb}$ level in $62 \%$ (70/113) of cases at birth and 54\% (35/65) of cases on day 2. 
TABLE 2

$\mathrm{Hb}$ Levels in Relation to Birth Order in Monochorionic Twin Pairs Delivered Vaginally or Through CS

\begin{tabular}{|c|c|c|c|c|c|c|c|}
\hline & \multicolumn{3}{|c|}{ Twin pairs delivered vaginally $(n=171)$} & \multicolumn{3}{|c|}{ Twin pairs delivered through CS $(n=119)$} & \multirow[b]{2}{*}{$p$ value } \\
\hline & Twin 1 & Twin 2 & $p$ value & Twin 1 & Twin 2 & $p$ value & \\
\hline $\mathrm{Hb}$ level at birth $-\mathrm{g} / \mathrm{dL}^{\mathrm{a}, \mathrm{b}}$ & $16.1 \pm 2.4$ & $17.8 \pm 2.5$ & $<.01$ & $15.9 \pm 2.2$ & $16.3 \pm 2.5$ & 10 & \\
\hline $\mathrm{Hb}$ level on day $2-\mathrm{g} / \mathrm{dL}^{\mathrm{a}, \mathrm{c}}$ & $14.8 \pm 2.7$ & $18.0 \pm 3.0$ & $<.01$ & $15.5 \pm 2.6$ & $16.0 \pm 2.8$ & .23 & \\
\hline $\mathrm{Hb}$ difference at birth $-\mathrm{g} / \mathrm{dL}^{\mathrm{a}, \mathrm{b}}$ & & $1.9(0.6-3.9)$ & & & $1.1(0.4-3.1)$ & & .02 \\
\hline $\mathrm{Hb}$ difference on day $2-\mathrm{g} / \mathrm{dL}^{\mathrm{a}, \mathrm{c}}$ & & $3.7(2.7-6.3)$ & & & $2.4(0.9-4.9)$ & & $<.01$ \\
\hline $\mathrm{Hb}$ difference $>8 \mathrm{~g} / \mathrm{dL}$ at birth $-n(\%)^{b}$ & & $9(5.2 \%)$ & & & $0(0.0 \%)$ & & $<.01$ \\
\hline $\mathrm{Hb}$ difference $>8 \mathrm{~g} / \mathrm{dL}$ on day $2-n(\%)^{\mathrm{c}}$ & & $11(6.4 \%)$ & & & $0(0.0 \%)$ & & $<.01$ \\
\hline
\end{tabular}

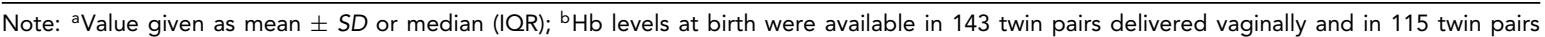
delivered through $\mathrm{CS}$. ${ }^{\mathrm{C}} \mathrm{Hb}$ levels on day 2 were available in 91 twin pairs delivered vaginally and in 64 twin pairs delivered through $\mathrm{CS}$. $\mathrm{Hb}=$ hemoglobin, $\mathrm{CS}=$ cesarean section.

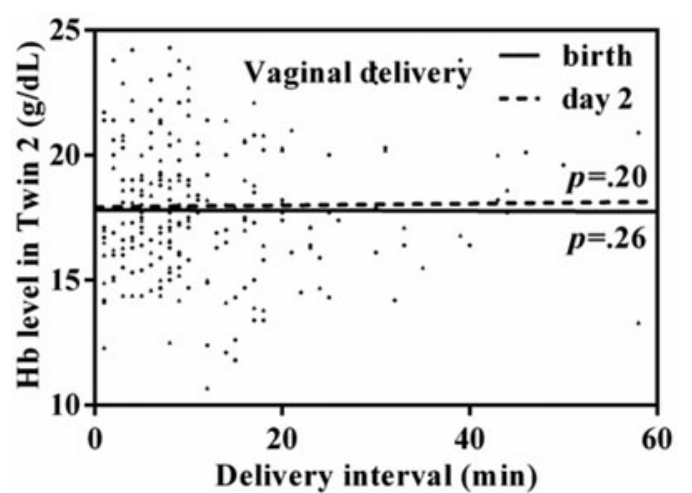

\section{FIGURE 1}

Hemoglobin level at birth and on day 2 in twin 2 in relation to delivery time interval.

The median time interval between the birth of twin 1 and twin 2 by means of vaginal delivery was 9 (IQR: 516) minutes. The median delivery time interval in the twins born through CS was 2 (IQR: 1-2) minutes. In both groups, no association between prolonged inter-twin delivery time interval and $\mathrm{Hb}$ level differences were found. We found no association between delivery time interval and $\mathrm{Hb}$ levels at birth or day 2 in second-born twins after vaginal delivery, as shown in Figure 1.

The rate of polycythemia was significantly higher in second-born twins compared to first-borns after vaginally delivery, $12 \%(20 / 166)$ versus $1 \%(2 / 166)(p<.01)$. No difference was detected in the CS group, 1\% (1/119) versus $0 \%(0 / 199 ; p=.99)$.

Acute peripartum TTTS (Hb difference $>8 \mathrm{~g} / \mathrm{dL}$ at birth) occurred in 5.2\% pregnancies (9/166) and was detected only in twin pairs after vaginal delivery. Second-born twins were always the recipient twins in case of acute peripartum TTTS. Further details on the clinical characteristics are listed in Table 3.

\section{Discussion}

This study showed that $\mathrm{Hb}$ differences at birth are a common finding in monochorionic twins born vaginally, even in the absence of TTTS or TAPS. We found that Hb differences are only present after vaginal delivery but not after CS, highlighting an important effect of mode of delivery. In addition, $\mathrm{Hb}$ levels are usually higher in second-born twins suggesting an important role of birth order. Our data suggest that inter-twin blood shifts may occur during vaginal delivery particularly towards the second twin.

Our findings confirm observations from a few small studies (Faxelius et al., 1977; Galea et al., 1982; Klebe \& Ingomar, 1972; Lopriore et al., 2005), although they differ from the findings of Bhide et al. (2006). While they found a trend towards a lower Hb level in a group of 20 second-born monochorionic twins, the small sample size may have hampered their conclusions (Bhide et al., 2006). In a previous, similar study from our research group, we found no association between mode of delivery and $\mathrm{Hb}$ differences (Lopriore et al., 2005). Again, the small study groups (28 twin pairs delivered vaginally and 17 pairs delivered through CS) prevented accurate statistical analyses. The large sample size in our present study reduces the risks of bias and may allow unraveling of the complex mechanisms that regulate inter-twin blood shifts during delivery. The other important strength of this study is that we were able to collect data for $\mathrm{Hb}$ levels at birth as well as on day 2. In general, $\mathrm{Hb}$ levels in neonates (whether singletons or twins) increase in the first few hours after birth. The initial short-term increase is due to hemoconcentration as plasma moves towards the extravascular space to compensate for the placental transfusion and increase in circulating red cell volume at the time of delivery. After several hours, Hb levels in neonates gradually decreases (Brans et al., 1981; Gairdner et al., 1958). In addition, in case of acute shifts of blood, initial $\mathrm{Hb}$ level measurements are known to be unreliable. When acute blood loss occurs, Hb levels initially remain stable due to vasoconstriction (Drucker et al., 1981). $\mathrm{Hb}$ levels reflecting the true blood loss can only be clearly detected after several hours, due to a compensatory mechanism of equilibration termed hemodilution. Hemodilution is a gradual increase in intravascular volume and plasma volume that takes place to compensate for acute blood loss (Saito et al., 2013). Conversely, when an infant receives an acute transfusion of blood, the expected rise in $\mathrm{Hb}$ levels 
TABLE 3

Clinical Outcome in Twins Born Through Vaginally Delivery and CS Delivery

\begin{tabular}{|c|c|c|c|c|c|c|}
\hline & \multicolumn{3}{|c|}{ Twins delivered through vaginal delivery } & \multicolumn{3}{|c|}{ Twins delivered through CS } \\
\hline & Twin $1 n=171$ & Twin $2 n=171$ & $p$ value & Twin $1 n=119$ & Twin $2 n=119$ & $p$ value \\
\hline Mortality — no. (\%) & $2(1 \%)$ & $4(2 \%)$ & .63 & $2(2 \%)$ & $5(4 \%)$ & .45 \\
\hline Polycythemia - no. $(\%)^{a}$ & $2(1 \%)$ & $20(12 \%)$ & $<.01$ & $0(0 \%)$ & $1(1 \%)$ & .99 \\
\hline Partial exchange transfusion - no. (\%) ${ }^{a}$ & $1(1 \%)$ & $4(3 \%)$ & .38 & $0(0 \%)$ & $1(1 \%)$ & .99 \\
\hline Blood transfusion - no. $(\%)^{\mathrm{a}}$ & $4(3 \%)$ & $2(1 \%)$ & .63 & $5(5 \%)$ & $2(2 \%)$ & .33 \\
\hline
\end{tabular}

Note: ${ }^{a}$ In first two days after birth. $\mathrm{CS}=$ cesarean section.

is only seen after several hours once equilibration between the intravascular and extravascular spaces is achieved. This is why we chose in this study to record Hb levels at birth as well as on day 2 .

Inter-twin $\mathrm{Hb}$ differences in monochorionic twins are known to be mediated through the invariable presence of placental vascular anastomoses connecting the two fetal circulations. Inter-twin $\mathrm{Hb}$ differences may already be present during pregnancy and can be associated with several disorders such as TAPS or TTTS. Inter-twin Hb differences may also occur during delivery in uncomplicated monochorionic twins. The exact pathophysiologic mechanism leading to inter-twin blood transfusion during delivery is not well known. Some authors suggested that uterine contractions or changes in fetal positioning may lead to inter-twin blood pressure differences and exacerbated inter-twin blood transfusion through the vascular anastomoses (Lehndorff, 1961; Sherer et al., 1992; Wenstrom et al., 1992). However, evidence for this hypothesis is lacking. Various other alternatives may explain the inter-twin $\mathrm{Hb}$ differences. In this study, we found a similar decrease in Hb levels (0.3$0.4 \mathrm{~g} / \mathrm{dL}$ ) between birth and day 2 in both first- and secondborn twins delivered through CS. In contrast, in twins born vaginally, the decrease in $\mathrm{Hb}$ level in first-born twins is more prominent $(1.3 \mathrm{~g} / \mathrm{dL})$ and is associated with a concomitant increase in $\mathrm{Hb}$ levels in second-born twins. The increase in $\mathrm{Hb}$ levels in second-born twins suggests that twin 2 may receive more blood during vaginal delivery. One hypothesis is that this increase in $\mathrm{Hb}$ level in twin 2 may result from blood transfusion from twin 1 to twin 2 during delivery (which could explain the significant decrease in $\mathrm{Hb}$ level in twin 1). Alternatively, the increase in $\mathrm{Hb}$ level in twin 2 may result from transfusion of blood from both placental shares into the circulation of the second twin (placentofetal transfusion) through the patent vascular anastomoses (Lopriore \& Oepkes, 2008; Lopriore et al., 2005). A third hypothesis is that the increase in Hb levels in second-born twins could be related to the time interval between delivery of twin 1 and twin 2 . Theoretically, prolonged time interval until delivery of twin 2 could be associated with increased placento-fetal transfusion towards twin 2 and explain the higher $\mathrm{Hb}$ levels in second born twins. However, our data do not support this theory since we found no association between prolonged delivery time interval and $\mathrm{Hb}$ levels in twin 2. Last, a fourth hypothesis is that the large $\mathrm{Hb}$ differences between twin 1 and twin 2 could be related to the timing of cord clamping. As shown in various studies, $\mathrm{Hb}$ levels at birth are strongly related with the timing of cord clamping. Late cord clamping ( $>30 \mathrm{~s}$ after birth) leads to higher $\mathrm{Hb}$ levels due to increased placento-fetal transfusion compared to early cord clamping (McDonald et al., 2013; Mercer, 2001; Rabe et al., 2012). Unfortunately, the timing of cord clamping was not recorded at our center and may vary between caregivers. Although it is tempting to assume that the time taken to clamp each cord was not different during delivery of each twin pair, it is possible that a difference could have occurred. Obstetricians may theoretically be tempted to clamp the cord of the first-born twin more quickly to focus their attention towards the sometimes more complicated delivery of the second twin. The significant drop in $\mathrm{Hb}$ level in twin 1 may be the result of relatively very early cord clamping resulting in reduced placento-fetal transfusion towards twin 1.

Although our study was not designed to assess the impact of timing of cord clamping, our data may have implications concerning the timing of cord clamping. Since second-born twins delivered vaginally have increased $\mathrm{Hb}$ levels and are more often at risk of polycythemia, delayed cord clamping may not be advisable in second-born twins. In contrast, since first-born twins have a significant decrease in $\mathrm{Hb}$ levels, early cord clamping should be avoided in first-born twins. Evidently, these suggestions must be tested in appropriately designed studies to evaluate the benefits of different cord-clamping strategies in this particular subgroup of monochorionic twins delivered vaginally.

Although our study is the largest study so far to analyze $\mathrm{Hb}$ levels in uncomplicated monochorionic twins, care should be taken when interpreting due to the retrospective nature of the study. Another limitation of our study is that $\mathrm{Hb}$ levels on day 2 were only measured in $53 \%$ of the included neonates and that timing of cord clamping was not recorded. Both findings are inherent to the retrospective nature of the study and should be taken into account when designing a prospective study in the future.

In conclusion, twins born second generally have higher $\mathrm{Hb}$ levels at birth and on day 2 when delivered vaginally, but no inter-twin $\mathrm{Hb}$ differences were detected after CS. Whether $\mathrm{Hb}$ differences result primarily from increase in 
Hb levels in twin 2 due to placento-fetal transfusion, decrease in $\mathrm{Hb}$ levels in twin 1 due to early cord clamping, or inter-twin blood shifts from twin 1 to twin 2 during delivery is not clear. Targeted studies to evaluate the optimal timing of cord clamping in monochorionic twins delivered vaginally are obviously required. Further studies are also necessary to determine the association between $\mathrm{Hb}$ differences in monochorionic twins and the number, type, and size of placental vascular anastomoses. These studies may improve our understanding of the pathophysiological mechanisms leading to blood shifts in monochorionic twins at birth.

\section{References}

Bhide, A., Prefumo, F., Sairam, S., Cobian-Sanchez, F., \& Thilaganathan, B. (2006). Effect of inter-twin delivery interval on neonatal haemoglobin concentration. Journal of Obstetrics and Gynaecology, 26, 759-762.

Brans, Y. W., Shannon, D. L., \& Ramamurthy, R. S. (1981). Neonatal polycythemia: II. Plasma, blood and red cell volume estimates in relation to hematocrit levels and quality of intrauterine growth. Pediatrics, 68, 175-182.

Drucker, W. R., Chadwick, C. D., \& Gann, D. S. (1981). Transcapillary refill in hemorrhage and shock. Archives of Surgery, 116, 1344-1353.

Faxelius, G., Raye, J., Gutberlet, R., Swanstrom, S., Tsiantos, A., Dolanski, E., ... Stahlman, M. (1977). Red cell volume measurements and acute blood loss in high-risk newborn infants. Journal of Pediatrics, 90, 273-281.

Gairdner, D., Marks, J., Roscoe, J. D., \& Brettell, R. O. (1958). The fluid shift from the vascular compartment immediately after birth. Archives of Disease in Childhood, 33, 489-498.

Galea, P., Scott, J. M., \& Goel, K. M. (1982). Feto-fetal transfusion syndrome. Archives of Disease in Childhood, 57, 781783.

Klebe, J. G., \& Ingomar, C. J. (1972). The fetoplacental circulation during parturition illustrated by the interfetal transfusion syndrome. Pediatrics, 49, 112-116.

Lehndorff, H. (1961). [Intrauterine hemorrhage from one twin into the other]. [Article in German]. Neue Osterr Z Kinderheilkd, 6, 163-172.

Lopriore, E., Holtkamp, N., Sueters, M., Middeldorp, J. M., Walther, F. J., \& Oepkes, D. (2014). Acute peripartum twintwin transfusion syndrome: Incidence, risk factors, placental characteristics and neonatal outcome. Journal of Obstetrics and Gynaecology Research, 40, 18-24.
Lopriore, E., \& Oepkes, D. (2008). Fetal and neonatal haematological complications in monochorionic twins. Seminars in Thrombosis and Hemostasis, 13, 231-238.

Lopriore, E., Sueters, M., Middeldorp, J. M., Oepkes, D., Vandenbussche, F. P., \& Walther, F. J. (2005). Neonatal outcome in twin-to-twin transfusion syndrome treated with fetoscopic laser occlusion of vascular anastomoses. Journal of Pediatrics, 147, 597-602.

Lopriore, E., Sueters, M., Middeldorp, J. M., Vandenbussche, F. P., \& Walther, F. J. (2005). Haemoglobin differences at birth in monochorionic twins without chronic twin-totwin transfusion syndrome. Prenatal Diagnosis, 25, 844850 .

McDonald, S. J., Middleton, P., Dowswell, T., \& Morris, P. S. (2013). Effect of timing of umbilical cord clamping of term infants on maternal and neonatal outcomes. Cochrane Database of Systematic Reviews, 7, CD004074.

Mercer, J. S. (2001). Current best evidence: A review of the literature on umbilical cord clamping. Journal of Midwifery \& Women's Health, 46, 402-414.

Rabe, H., Diaz-Rossello, J. L., Duley, L., \& Dowswell, T. (2012). Effect of timing of umbilical cord clamping and other strategies to influence placental transfusion at preterm birth on maternal and infant outcomes. Cochrane Database of Systematic Reviews, 8, CD003248.

Rosenkrantz, T. S. (2003). Polycythemia and hyperviscosity in the newborn. Seminars in Thrombosis and Hemostasis, 29, 515-527.

Saito, F., Shimazu, T., Miyamoto, J., Maemura, T., \& Satake, M. (2013). Interstitial fluid shifts to plasma compartment during blood donation. Transfusion, 53, 2744-2750.

Senat, M. V., Deprest, J., Boulvain, M., Paupe, A., Winer, N., \& Ville, Y. (2004). Endoscopic laser surgery versus serial amnioreduction for severe twin-to-twin transfusion syndrome. New England Journal of Medicine, 351, 136-144.

Sherer, D. M., Sinkin, R. A., Metlay, L. A., \& Woods, J. R., Jr. (1992). Acute intrapartum twin-twin transfusion. A case report. Journal of Reproductive Medicine, 37, 184-186.

Slaghekke, F., Kist, W. J., Oepkes, D., Pasman, S. A., Middeldorp, J. M., Klumper, F. J., ... Lopriore, E. (2010). Twin anemia-polycythemia sequence: Diagnostic criteria, classification, perinatal management and outcome. Fetal Diagnosis and Therapy, 27, 181-190.

Wenstrom, K. D., Tessen, J. A., Zlatnik, F. J., \& Sipes, S. L. (1992). Frequency, distribution, and theoretical mechanisms of hematologic and weight discordance in monochorionic twins. Obstetrics \& Gynecology, 80, 257-261. 